\title{
Development of the bronchial epithelial reticular basement membrane: relationship to epithelial height and age
}

\author{
Lemonia Tsartsali, ${ }^{1}$ Alison A Hislop, ${ }^{2}$ Karen McKay, ${ }^{3}$ Alan L James, ${ }^{4}$ John Elliot, ${ }^{4}$ \\ Jie Zhu, ${ }^{5}$ Mark Rosenthal, ${ }^{1}$ Donald N Payne, ${ }^{6}$ Peter K Jeffery, ${ }^{5}$ Andrew Bush, \\ Sejal Saglani ${ }^{1}$
}

- Additional figures are published online only. To view these files please visit the journal online (http://thorax.bmj. com).

${ }^{1}$ Respiratory Paediatrics, Royal Brompton Hospital, Imperial College London, London, UK

2Developmental Vascular Biology, University College London, Institute of Child Health, London, UK

${ }^{3}$ Respiratory Medicine

Children's Hospital at

Westmead, The University of

Sydney, New South Wales,

Australia

${ }^{4}$ West Australian Sleep Disorders Research Institute Perth, Western Australia ${ }^{5}$ Lung Pathology, Department of Gene Therapy, Imperial College London, London, UK

${ }^{6}$ School of Paediatrics and Child Health, The University of Western Australia, Australia

Correspondence to

Dr Sejal Saglani, Imperial College London, National Heart \& Lung Institute, 374 Sir Alexander Fleming Building, Exhibition Road, London SW7 2AZ, UK

s.saglani@imperial.ac.uk

Received 24 August 2010 Accepted 9 December 2010 Published Online First 13 January 2011

\section{ABSTRACT}

Background The bronchial epithelium and underlying reticular basement membrane (RBM) have a close spatial and functional inter-relationship and are considered an epithelial-mesenchymal trophic unit (EMTU). An understanding of RBM development is critical to understanding the extent and time of appearance of its abnormal thickening that is characteristic of asthma.

Methods RBM thickness and epithelial height were determined in histological sections of cartilaginous bronchi obtained postmortem from 47 preterm babies and infants (median age 40 weeks gestation (22 weeks gestation-8 months)), 40 children (2 years (1 month-17 years)) and 23 adults (44 (17-90) years) who had died from non-respiratory causes, and had no history of asthma.

Results The RBM was visible by light microscopy at 30 weeks gestation. RBM thickness increased in successive age groups in childhood; in infants $(r=0.63$, $\mathrm{p}<0.001$ ) and in children between 1 month and 17 years $(r=0.82, p<0.001)$. After 18 years, RBM thickness decreased with increasing age $(r=-0.42, p<0.05)$. Epithelial height showed a similar relationship with age, a positive relationship from preterm to 17 years $(r=0.50$, $p<0.001)$ and a negative relationship in adulthood $(r=-0.84, p<0.0001)$. There was a direct relationship between epithelial height and RBM thickness $(r=0.6$, $\mathrm{p}<0.001$ )

Conclusions The RBM in these subjects was microscopically identifiable by 30 weeks gestation. It thickened during childhood and adolescence. In adults there was either no relationship with age, or a slow reduction in thickness in older age. Developmental changes of RBM thickness were accompanied by similar changes in epithelial height, supporting the close relationship between RBM and epithelium within the EMTU.

\section{BACKGROUND}

The bronchial epithelial basement membrane is an acellular matrix composed of two structurally distinct layers, the basal lamina and the lamina reticularis or reticular basement membrane (RBM). The RBM is not present in healthy airways of all species. It is not present in rodents, but is present in cats, pigs, sheep ${ }^{1}$ and non-human primates. $^{2}$ Its function and the reason for its presence in healthy humans remain unclear. Abnormal thickening of the RBM is a feature of airway remodelling seen in several inflammatory airway diseases and is especially characteristic of asthma. Biopsy studies in adults, ${ }^{3}$ children with severe ${ }^{4}$ and mild to moderate asthma $^{5}$ and preschool children with severe wheezing $^{6}$ have each reported increased RBM thickening as compared with non-asthma controls. Importantly, it has been proposed that direct interaction between the epithelium and underlying RBM is critical in the pathogenesis of asthma, and that they function as a single unit, the epithelialmesenchymal trophic unit (EMTU). ${ }^{7}$ Although an increase in epithelial height in the first 8 months of life has been reported, ${ }^{8}$ subsequent changes in epithelial height with age are unknown. The relationship between RBM thickness and epithelial height during development of the EMTU has also not been investigated.

There are presently no data in humans on the timing of the first appearance and development of the bronchial epithelial RBM. Studies in monkeys have shown that the RBM develops postnatally, and is visible by light microscopy at 1 month postpartum, thickens further by 3 months and achieves final adult thickness by 6 months of age. ${ }^{9}$ Our current knowledge of normal RBM thickness in humans comes from endobronchial biopsy studies that have compared RBM thickness in patients with inflammatory airway conditions with controls. Ethical limitations mean only adult studies can include healthy volunteers as controls, and the range of reported normal values for RBM thickness in adult endobronchial biopsies is between $3.2 \mu \mathrm{m}^{10}$ and $8.4 \mu \mathrm{m} .{ }^{11}$ In children, as endobronchial biopsy cannot be justified in healthy subjects, most studies have used surrogate controls, including children with isolated upper airway symptoms (stridor), ${ }^{6}$ and those with recurrent pneumonia or haemoptysis. ${ }^{4}$ To overcome the difficulty in obtaining tissue from healthy children, we used postmortem tissue from non-respiratory deaths which had been collected for clinical reasons. Importantly, RBM thickness measured in cartilaginous airways in autopsy tissue from adults with and without asthma has been shown to be similar to that measured in endobronchial biopsies taken from central airways. ${ }^{12}$ We hypothesised that the RBM is first visible at birth, thickens normally during the first few years of life and subsequently plateaus during school age, having by then reached its maximum normal thickness. We also reasoned that due to the close inter-relationship proposed 
between the RBM and overlying epithelium, changes in RBM thickness might be reflected by alterations in epithelial height.

\section{METHODS \\ Subjects}

Autopsy lung tissue was obtained from 47 fetuses and infants from London, UK (aged 22 weeks gestation to 8 months old) who were stillborn or had died suddenly without specific cause, 40 children from Sydney, Australia (aged 1 month to 17 years) and 23 adults from Perth, Australia (aged 17-90 years). All had undergone a postmortem examination for clinical reasons to establish the cause of death. In no case did the postmortem report reveal a primary lung abnormality or evidence of a history or pathological abnormalities of asthma or chronic obstructive pulmonary disease (COPD). Approval to use the tissue for the purpose of research had been obtained from the local ethics committees, and the laws on importation and research testing of human tissue obtained at autopsy had been complied with.

\section{Tissue processing and staining}

Lungs were collected and processed for histology as part of the postmortem study. Lungs from London and Sydney were fixed in $10 \%$ formalin; those from Perth were fixed in $10 \%$ paraformaldehyde. Tissue from London and Perth was fixed in inflation while that from Sydney was fixed by immersion. To exclude differences in RBM thickness resulting from fixation techniques, measurements from the three centres have been plotted separately. Tissue was stored in fixative for up to 6 months and processed through to wax embedding. $5 \mu \mathrm{m}$ thick sections were cut and stained with $\mathrm{H} \& \mathrm{E}$ and used to quantify RBM thickness and epithelial height, and to measure internal airway perimeter. ${ }^{13}$

\section{RBM measurement in whole airways}

RBM thickness in tissue from London and Perth was measured by SS, while tissue from Sydney was measured by LT. Both observers were unaware of the subjects' clinical details. Interobserver agreement for measurements made in infants and children was assessed by a Bland-Altman plot of measurements from four airways performed by both observers (figure E1 online). RBM measurement was based on a previously validated method used in adult ${ }^{14}$ and paediatric ${ }^{4}$ endobronchial biopsies, and a previously described method from a study of whole airways in postmortem tissue. ${ }^{12}$ In order to limit the influence of airway size per se and to reflect the proximal airways accessed in endobronchial biopsy studies, all airways measured were intrapulmonary and cartilaginous, and those of approximately the third generation were measured when available. Sections were selected if the following additional criteria were satisfied: (1) airways had identifiable epithelium (as epithelium was stripped in some airways) and (2) airways were cut in a plane transverse to their length. Colour images of airways that satisfied these criteria were obtained with a digital camera (Zeiss Axiocam, Thame, UK). RBM thickness was measured using computer-aided image analysis (Openlab v3.02 software, Improvision, Coventry, UK). The internal airway perimeter was measured at a magnification of $\times 50$ (figure $1 \mathrm{~A}$ ). Subsequently, four images (including epithelium, RBM and submucosal region) were taken at a magnification of $\times 400$ from a random starting point and then at $90^{\circ}$ intervals to allow measurement of RBM thickness and epithelial height. If the RBM could not be recognised anywhere along the airway, this was noted as a thickness of $0 \mu \mathrm{m}$. A line was drawn as a tangent to the outer (submucosal) edge of the RBM. RBM thickness was defined, measured and recorded along a line drawn towards the airway lumen, perpendicular to the tangent (figure 1B). A total of 40 measurements, $20 \mu \mathrm{m}$ apart, were obtained from each airway, and the geometric mean was used to represent RBM thickness for that airway. If the RBM could be identified, but was too thin to be measured by the image analysis software, a score of $0.01 \mu \mathrm{m}$ was recorded, and included in the final averaging of measurements. Between one and four airways were measured for each subject. The mean value from all airways was used for each subject when more than one airway was measured. The within-subject, between-airway coefficient of variation of RBM thickness in subjects with $\geq 3$ analysable airways ranged between $5 \%$ and $23 \%$.

\section{Measurement of epithelial height}

Bronchial epithelial height was measured using computer-aided image analysis at a magnification of $\times 400$. Only intact epithelium, attached to the basement membrane along at least $0.5 \mathrm{~mm}$ length of the airway, was included. Epithelial height was measured from the luminal edge of the RBM to the luminal surface of a single cell, excluding cilia. The mean height of at least 10 cells from four different regions of the airway was taken to represent epithelial height for that airway.

\section{Determination of airway size}

Airway size was determined by assessment of its inner circumference, measured at magnification $\times 50$ along the epithelial luminal edge (henceforth referred to as airway perimeter).

\section{Statistical analysis}

Linear relationships were assessed using Spearman rank correlation, with $\mathrm{p}<0.05$ considered as statistically significant.
Figure 1 (A) H\&E-stained section showing a whole cartilaginous airway in which reticular basement membrane (RBM) thickness and epithelial height were measured (magnification $\times 50$ ). (B) High magnification $(\times 400)$ image of part of the airway in A showing RBM thickness.
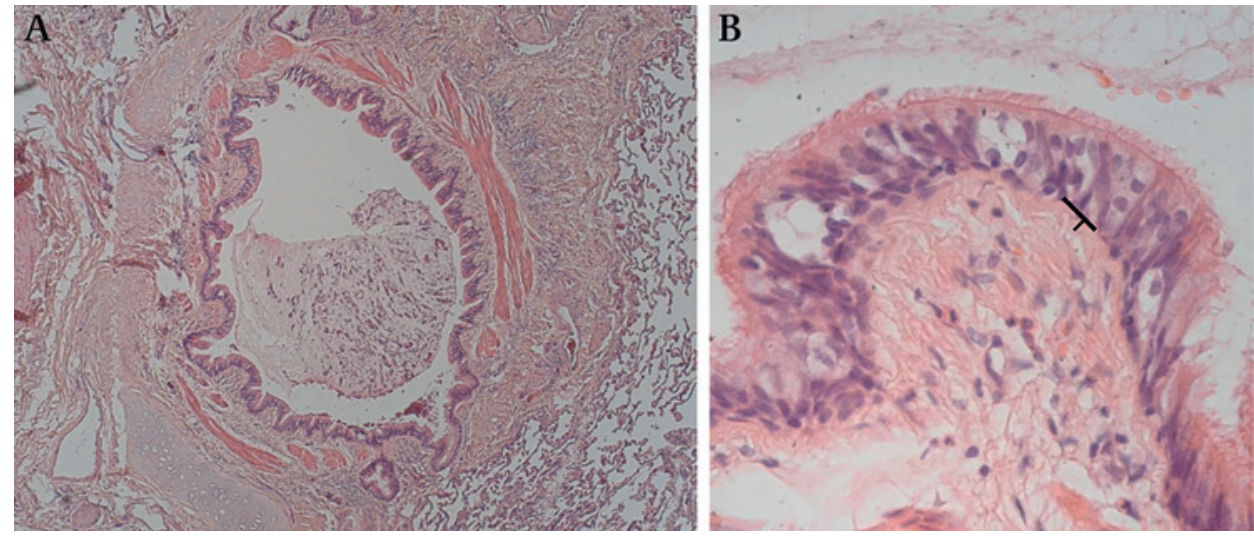
Table 1 Number, gender, height and weight of subjects in each age group

\begin{tabular}{|c|c|c|c|c|c|c|}
\hline \multirow[b]{2}{*}{ Age at death } & \multicolumn{3}{|c|}{ Number and origin } & \multirow{2}{*}{$\begin{array}{l}\text { Gender } \\
\text { (M/F) }\end{array}$} & \multirow{2}{*}{$\begin{array}{l}\text { Height (cm) } \\
\text { (median/range) }\end{array}$} & \multirow{2}{*}{$\begin{array}{l}\text { Weight (kg) } \\
\text { (median/range) }\end{array}$} \\
\hline & UK & Sydney & Perth & & & \\
\hline $22-25$ weeks & 3 & - & - & $1 / 2$ & $29(28.5-31)$ & $0.58(0.51-0.61)$ \\
\hline $26-30$ weeks & 3 & - & - & $1 / 2$ & $31.5(30.5-39)$ & $0.77(0.57-1.27)$ \\
\hline $31-35$ weeks & 8 & - & - & $7 / 1$ & $45.5(41.5-48.5)$ & $2(1.5-2.8)$ \\
\hline 36-39 weeks & 7 & - & - & $5 / 2$ & $47(41.5-54.5)$ & $2.6(2.2-4.1)$ \\
\hline Term-3 months & 16 & 4 & - & $13 / 7$ & $54.3(32.5-66)$ & $3.9(0.9-6.9)$ \\
\hline $3-6$ months & 6 & 3 & - & $7 / 2$ & $60.5(56-66)$ & $5.9(4.1-9.1)$ \\
\hline $6-12$ months & 4 & 3 & - & $4 / 2^{*}$ & $70(66-74)$ & $8(6.3-9.4)$ \\
\hline 12 months -2 years & - & 7 & - & $7 / 0$ & $80(58-85)$ & $11.1(4.3-14)$ \\
\hline $2-6$ years & - & 12 & - & $5 / 7$ & $100(88-119)$ & $18.5(9.3-29)$ \\
\hline $6-17$ years & - & 11 & 1 & $6 / 6$ & $161(108-174)$ & $49(17-62)$ \\
\hline $18-40$ years & - & - & 10 & $10 / 0$ & $176(163-193)$ & $75.5(52-109)$ \\
\hline $41-90$ years & - & - & 12 & $5 / 7$ & $160(148-178)$ & $62.5(37-90)$ \\
\hline Total & 47 & 40 & 23 & & & \\
\hline
\end{tabular}

*Gender not recorded in one infant.

$F$, female; $M$, male.

Intraobserver repeatability of measurements was assessed by calculating the coefficient of variation (\%) of measuring four airways on three different occasions. This ranged from $5.4 \%$ to $8.5 \%$ for SS and from $2.7 \%$ to $8.1 \%$ for LT. Data were analysed using SPSS version 11.5.

\section{RESULTS}

\section{Demographics}

The median age at death for all fetuses and infants from London was 40 weeks gestation (range 22 weeks gestation-8 months), that for all children from Sydney was 2.3 years (range 1 month-17 years) and that for adults from Perth was 44 (range 18-90) years. Table 1 summarises the demographics of the subjects in the different age groups. Table 2 shows the cause of death for all subjects.

\section{Relationship between RBM thickness and age}

The RBM was not visible by light microscopy in 4 of the 27 preterm infants. It was only visible in one infant under 30 weeks gestation, but after this time it was visible in all preterm and post-term subjects. The association of RBM thickness and age is shown in figure $2 \mathrm{~A}-\mathrm{C}$. When only preterm infants were assessed, RBM thickness was positively associated with age until term $(\mathrm{r}=0.6, \mathrm{p}<0.001)$. From birth to age 8 months (London tissue), there was an increase in RBM thickness with age $(r=0.63, p<0.001)$ (figure $2 A)$. There was also a positive correlation between RBM thickness and age from infancy to age

Table 2 Cause of death

\begin{tabular}{lc}
\hline Cause of death & No. of cases \\
\hline Stillbirth & 21 \\
Sudden infant death syndrome & 36 \\
Head injury & 9 \\
Meningococcal sepsis & 2 \\
Drowning & 4 \\
Smoke/CO inhalation & 6 \\
Multiple injuries & 5 \\
Asphyxiation/hanging & 5 \\
Cardiac disease & 7 \\
Motor vehicle accident & 6 \\
Neurological disease & 2 \\
Drug overdose & 2 \\
Complications of Denys-Drash syndrome & 1 \\
Undetermined & 4 \\
\hline
\end{tabular}

17 years (Sydney tissue) $(\mathrm{r}=0.82, \mathrm{p}<0.001)$ (figure $2 \mathrm{~B})$. Subsequently, from 18 years onwards (Perth tissue), there was a weak negative association between RBM thickness and age (Spearman $\mathrm{r}=-0.42, \mathrm{p}<0.05$ ) (figure $2 \mathrm{C}$ ). When only tissue from Sydney was considered, the variance of RBM thickness in children $\geq 6$ years old was significantly higher than in the younger group (variance ratio (F-test): $3.08, \mathrm{p}<0.001$ ), suggesting that the rate of increase was greater in those under 6 years than in those over 6 years old.

\section{Relationships between epithelial height, RBM thickness and age}

Epithelial height could be measured in $43 / 47$ fetuses and infants (London tissue), 10/40 children (Sydney tissue) and 18/23 adults (Perth tissue). For airways in which epithelial height could be measured, there was a direct relationship between RBM thickness and epithelial height (Spearman $\mathrm{r}=0.6, \mathrm{p}<0.001$ ) (figure $3 \mathrm{~A}$ ). The relationships between epithelial height and age, and RBM thickness and age were similar (figure 3B-D). A positive relationship was apparent between age and epithelial height until 17 years (Spearman $\mathrm{r}=0.5, \mathrm{p}<0.01$ ) and a negative relationship between age and epithelial height after 18 years (Spearman $\mathrm{r}=-0.84, \mathrm{p}<0.001$ ).

\section{Relationship between RBM thickness and airway size}

Airways were chosen to reflect proximal airway generations from which endobronchial biopsies are taken. There was a positive relationship between internal airway perimeter and RBM thickness in Sydney children (Spearman $\mathrm{r}=0.576, \mathrm{p}=0.001$ ) (figure 4B). These specimens were fixed in immersion. There was no relationship between internal airway perimeter and RBM thickness in the infants (from London) or adults (from Perth) (figure 4A,C). Specimens from both of these centres were fixed in inflation. In order to determine whether the relationship between RBM thickness and age held true for the Sydney children, or whether the result might be confounded by the possibility of larger airways in older children, we determined the relationship between age and airway size. There was no significant relationship between age and airway size in any of the groups measured (figures 5A,B), thus supporting a true relationship between age and $\mathrm{RBM}$ thickness.

\section{Relationship between gender, height and RBM thickness}

RBM thickness was similar in males and females of similar ages (figure E2, online). There was a positive relationship between 

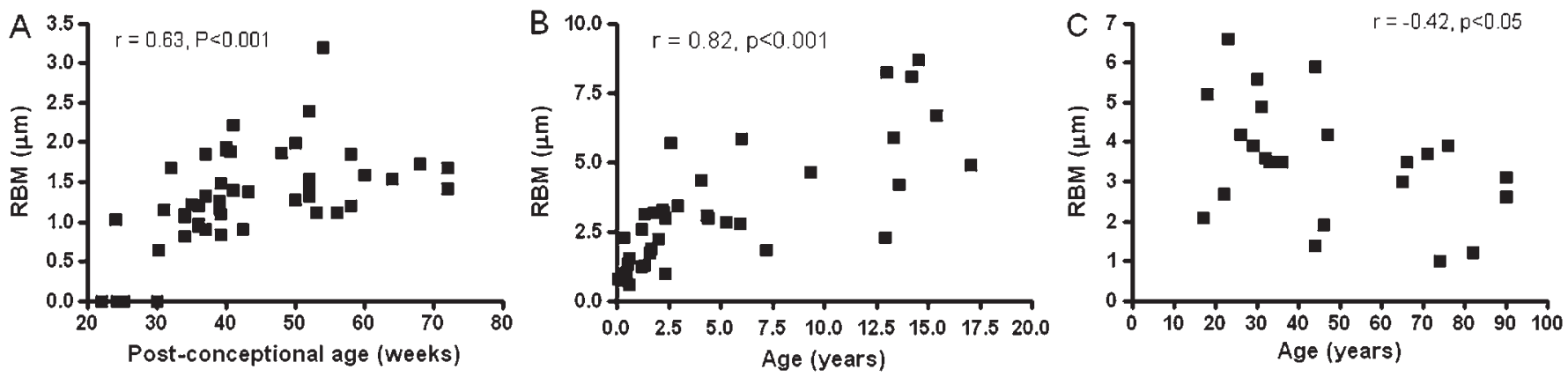

Figure 2 Relationship between reticular basement membrane (RBM) thickness and age. (A) Change in RBM thickness with increasing age in fetuses and infants (tissue from London). (B) Increasing RBM thickness with age in children (tissue from Sydney). (C) Slow decrease in RBM thickness during adulthood (tissue from Perth).

RBM thickness and subject height in the infants (Spearman $\mathrm{r}=0.54, \mathrm{p}<0.001$ ) and children (Spearman $\mathrm{r}=0.84, \mathrm{p}<0.001)$, but not in the adults (Spearman $\mathrm{r}=0.37, \mathrm{p}=0.08$ ) (figure $\mathrm{E} 3$, online). There was no relationship between subject height and airway size in any of the age groups.

\section{DISCUSSION}

This is the first description of the time of first appearance and subsequent quantitative development of the RBM in humans without known respiratory disease. We have shown in our group of selected individuals that the RBM is difficult to discern by light microscopy before 30 weeks gestation, whereas between 30 weeks gestation and term, the RBM is visible in all of the cases studied. RBM thickness increases with age until term, subsequently increases rapidly until about 6 years of age and then continues to increase, but at a slower rate, until about 17 years. However, the large variability in RBM thickness between individuals after school age prevents the clear delineation of an age when its increase plateaus. In adulthood, RBM thickness appears to decrease gradually with age. We show for the first time a strong relationship between RBM thickness and epithelial height, and the change in epithelial height with age reflects the change in RBM thickness with age. These data support the proposed close interaction of the epithelium with its underlying RBM and their association as an EMTU. ${ }^{15}$

The first detection of the RBM by light microscopy $\sim 10$ weeks before term (with one subject having a visible RBM at 24 weeks gestation) is consistent with a previous report of it being visible only by electron microscopy after $\sim 24$ weeks gestation. ${ }^{16}$ It also highlights a key difference in RBM development between humans and primates, since in the latter it develops postnatally. ${ }^{2}$ The slope of the linear relationship between age and RBM thickness is steep from 30 weeks gestation up to 6 years of age (figure 2A,B), indicating a relatively rapid rate of increasing $\mathrm{RBM}$ thickness during this period. This is consistent with the rate of total lung growth which is fastest during the first 2 years of life, due primarily to alveolar multiplication. ${ }^{17}$ Alveoli also first appear in utero at $\sim 30$ weeks gestation. ${ }^{18}$ Alveolar formation/maturation is controlled by interaction with the subepithelial elastin-collagen matrix, which acts as an anchoring fishnet through which alveoli protrude (ie, the 'fishnet hypothesis'). ${ }^{19}$ The similar timing of onset of such a maturation process in the lung parenchyma and the appearance and rapid increase of bronchial RBM thickness suggests that both may be influenced by molecular changes in their adjacent lung connective tissue matrices.
Figure 3 Relationship between epithelial height, reticular basement membrane (RBM) thickness and age. (A) A direct positive relationship between epithelial height and RBM thickness. (B) Pattern of development of epithelial height with age in all subjects. (C) Increasing epithelial height with age in children less than 17 years old. (D) Reducing epithelial height with increasing age in adults.
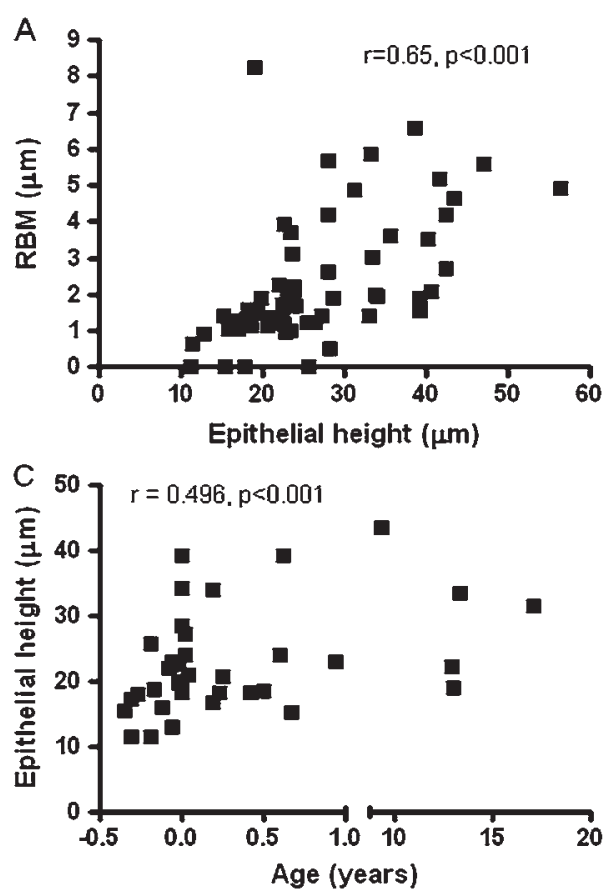
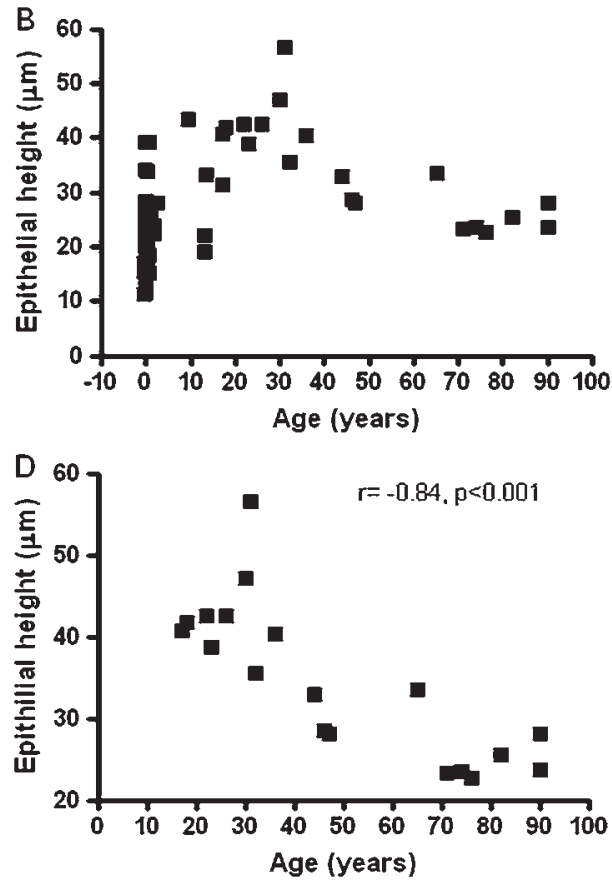

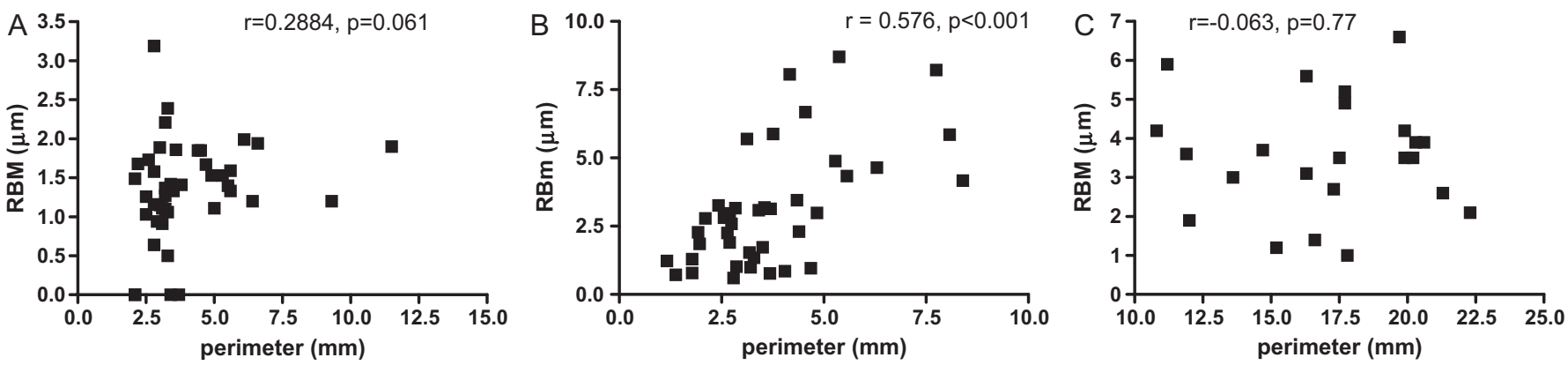

Figure 4 Relationship between reticular basement membrane (RBM) thickness and airway perimeter. (A) No relationship between RBM thickness and airway perimeter in fetuses and infants (London tissue). (B) Positive relationship between airway perimeter and RBM thickness in children (Sydney tissue). (C) No relationship between airway size and RBM thickness in adults (Perth tissue).

We were unable to define clearly an age when maximal RBM thickness is reached. From our cross-sectional data it seems that the RBM increases in thickness, albeit at a slower rate after 6 years, without a definite plateau in thickness being reached until at least adolescence. The 'soft plateau' that we have seen in RBM thickening is also observed in normal alveolar development, whereby the exact time at which alveolar growth and multiplication ceases is unknown. ${ }^{20}$ This is the first report of a possible reduction in RBM thickness apparent during ageing, which interestingly is also mirrored in an age-associated reduction of alveolar surface area and wall tissue. ${ }^{2021}$

This is the first description of change in epithelial height with age, and the first report of a positive relationship between RBM thickness and epithelial height. We speculate that as taller epithelial columnar cells develop, a function of the basement membrane may be to keep them anchored, and thus a thickening of the reticular component of the basement membrane may be required to help achieve this. Indeed the contact area between columnar cells and the basal lamina in subjects with asthma is significantly less than in healthy controls ${ }^{22}$ and is a proposed explanation for epithelial shedding in asthma. Increasing bronchial epithelial height with age has previously been reported from preterm until 8 months postnatal age, ${ }^{23}$ but subsequent changes in epithelial height with age were unknown. We have shown an increase in epithelial height until adolescence, with a subsequent reduction during adulthood. However, the number of adults included in our study is small, and the relationship between RBM thickness and age in adults is only weakly negative; therefore, it is difficult to draw definitive conclusions about change in RBM thickness and epithelial height with age in our adults. This relationship needs to be investigated further in future studies with a larger sample size. If confirmed, these features may be a reflection of the normal decline in lung function seen in adults. The lack of consensus about a relationship between $\mathrm{RBM}$ thickness and lung function may be explained by failure to take account of a natural reduction in RBM thickness in adulthood. Thus to allow accurate and meaningful interpretation of RBM data obtained in studies of endobronchial biopsies, it would seem important to include age-matched controls for children and adults.

One limitation of our current study is that we have not assessed changes in the components of the RBM with its development, which might provide clues to the important molecules and mechanisms involved. We have tried staining these formalin-fixed, paraffin wax-embedded sections for at least one RBM component, tenascin-C, but have been unsuccessful. While previous studies have reported RBM components, these have all used snap-frozen tissue, but as we only had access to paraffin sections we have been unable to explore this further. However, the importance of fibroblast growth factor in contributing to increased thickness and the role of the RBM in influencing trafficking of growth factors in the EMTU has been shown in primate airways. ${ }^{2}$ A further limitation is the use of light microscopy alone, and not additional electron microscopy to assess RBM ultrastructure. Although this may have shown the presence of a reticular layer earlier than 30 weeks gestation, such a study was not possible because all tissue was processed for clinical reasons, fixed and embedded in paraffin wax, not the resin embedding required for electron microscopy. However, we have previously reported on the ultrastructure of the RBM in non-wheezy infants, children without asthma and healthy adults, and shown that it is similar at all ages. ${ }^{24}$ We acknowledge that our postmortem lung specimens were not all fixed using the same technique, and this is why the data have been presented in three separate age groups, according to the origin of the tissue. Finally, we accept there is inequality in the number of subjects in each age group, with only small numbers available at some ages, especially the older children and adults. However, the nature of
Figure 5 Relationship between airway perimeter and age. (A) No relationship between airway perimeter and age in subjects from preterm up to 17 years old. (B) No relationship between airway perimeter and age in adults 18 years and older.
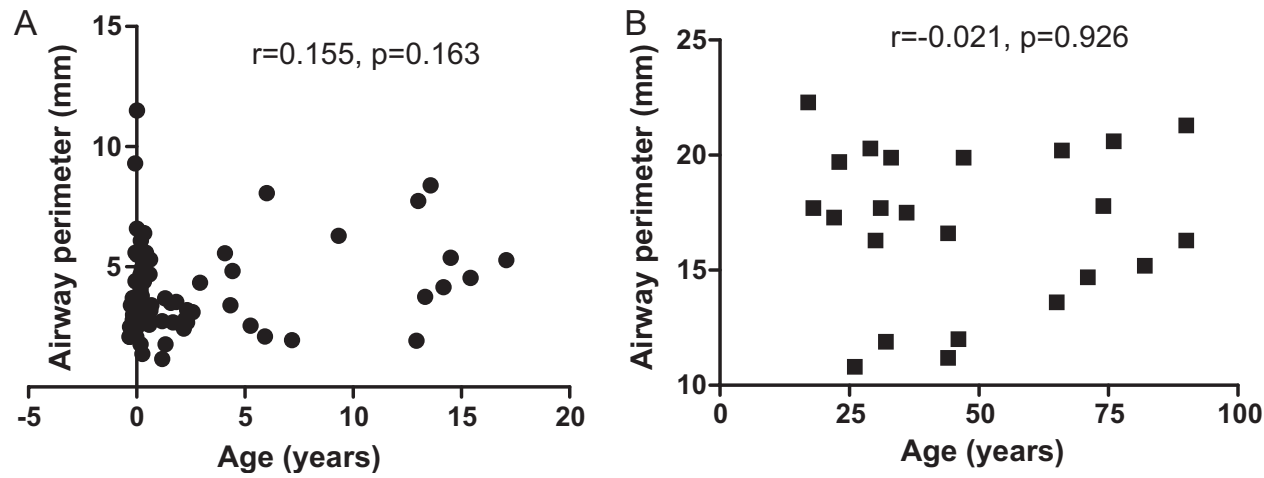
the tissue is such that we were unable to have an equal age distribution. We also acknowledge that the three age groups are made up of subjects from different areas, and that these are not longitudinal data. Despite the above limitations, we consider the large number of subjects, whose deaths were not respiratory related, and the wide age range included provides a strong basis for establishing the time of appearance and pattern of thickening that occurs to the bronchial RBM, and its positive relationship with epithelial height, during normal development. These data indicate that future paediatric and adult biopsy studies assessing RBM thickness should include age-matched controls.

Funding The British Paediatric Respiratory Society, Asthma UK, The Wellcome Trust, UK. SS is funded by an Intermediate Clinical Fellowship from the Wellcome Trust. AJ is supported by a National Health and Medical Research Council of Australia Practitioner Fellowship.

Competing interests None.

Ethics approval This study was conducted with the approval of the local ethics committees at each centre from which tissue was obtained.

Provenance and peer review Not commissioned; externally peer reviewed.

\section{REFERENCES}

1. Kirschvink N, Reinhold P. Use of alternative animals as asthma models. Curr Drug Targets 2008; : :470-84

2. Evans MJ, Fanucchi MV, Plopper CG, et al. Postnatal development of the lamina reticularis in primate airways. Anat Rec (Hoboken) 2010;293:947-54.

3. Jeffery PK. Remodeling in asthma and chronic obstructive lung disease. Am J Respir Crit Care Med 2001:164:S28-38.

4. Payne DN, Rogers AV, Adelroth E, et al. Early thickening of the reticular basement membrane in children with difficult asthma. Am J Respir Crit Care Med 2003:167:78-82.

5. Barbato A, Turato G, Baraldo $\mathrm{S}$, et al. Airway inflammation in childhood asthma. Am J Respir Crit Care Med 2003:168:798-803.

6. Saglani S, Payne DN, Zhu J, et al. Early detection of airway wall remodeling and eosinophilic inflammation in preschool wheezers. Am J Respir Crit Care Med 2007:176:858-64.
7. Holgate ST, Davies DE, Lackie PM, et al. Epithelial-mesenchymal interactions in the pathogenesis of asthma. J Allergy Clin Immunol 2000;105:193-204.

8. Hislop AA, Haworth SG. Airway size and structure in the normal fetal and infant lung and the effect of premature delivery and artificial ventilation. Am Rev Respir Dis 1989;140:1717-26

9. Evans MJ, Fanucchi MV, Van Winkle LS, et al. Fibroblast growth factor-2 during postnatal development of the tracheal basement membrane zone. Am J Physiol Lung Cell Mol Physiol 2002;283:L1263-70.

10. Wilson JW, Li X. The measurement of reticular basement membrane and submucosal collagen in the asthmatic airway. Clin Exp Allergy 1997;27:363-71.

11. Jeffery PK, Godfrey RW, Adelroth E, et al. Effects of treatment on airway inflammation and thickening of basement membrane reticular collagen in asthma. A quantitative light and electron microscopic study. Am Rev Respir Dis 1992;145:890-9.

12. James AL, Maxwell PS, Pearce-Pinto G, et al. The relationship of reticular basement membrane thickness to airway wall remodeling in asthma. Am J Respir Crit Care Med 2002:166:1590-5

13. James AL, Pare PD, Hogg JC. The mechanics of airway narrowing in asthma. Am Rev Respir Dis 1989;139:242-6.

14. Sullivan $\mathbf{P}$, Stephens D, Ansari T, et al. Variation in the measurements of basement membrane thickness and inflammatory cell number in bronchial biopsies. Eur Respir $J$ 1998:12:811-15.

15. Holgate ST. Has the time come to rethink the pathogenesis of asthma? Curr Opin Allergy Clin Immunol 2010;10:48-53.

16. Jeffery PK. Embryology and growth of the normal lung. In: Brewis RAL, Gibson GJ, Geddes D, eds. Respiratory Medicine. London: Bailliere Tindall, 1990:3-20.

17. Thurlbeck WM. Postnatal human lung growth. Thorax 1982;37:564-71

18. Hislop AA, Wigglesworth JS, Desai $\mathrm{R}$, et al. The effects of preterm delivery and mechanical ventilation on human lung growth. Early Hum Dev 1987;15:147-64.

19. Emery JL, Mithal A. The number of alveoli in the terminal respiratory unit of man during late intrauterine life and childhood. Arch Dis Child 1960:35:544-7.

20. Thurlbeck WM, Angus GE. Growth and aging of the normal human lung. Chest 1975;67(2 Suppl):3S-6S.

21. Ochs $\mathbf{M}$, Nyengaard JR, Jung A, et al. The number of alveoli in the human lung. Am J Respir Crit Care Med 2004;169:120-4.

22. Shebani E, Shahana S, Janson C, et al. Attachment of columnar airway epithelial cells in asthma. Tissue Cell 2005;37:145-52.

23. Haworth SG, Hislop AA. Lung development-the effects of chronic hypoxia. Semin Neonatol 2003:8:1-8.

24. Saglani S, Molyneux C, Gong H, et al. Ultrastructure of the reticular basement membrane in asthmatic adults, children and infants. Eur Respir $\mathrm{J}$ 2006:28:505-12.

\section{An unusual cause of chest pain}

\section{INTRODUCTION}

A 19-year-old male patient with a history of asthma was in good health until he developed a sudden-onset, right side pleuritic chest discomfort and shortness of breath. At that time, he was on a cruise to Puerto Rico. He returned home 1 week later and was evaluated in the emergency room at that time. On further history, he denied cough, fever, chills, night sweats, weight loss, sputum production, haemoptysis or other symptoms. He did not recall recent sick contacts or exposure to tuberculosis. He was born in the USA and this cruise was his only recent travel. He worked in a law firm and denied significant occupational exposures, any tobacco or drug use, allergies or significant family
Figure 1 (A) Chest radiograph showing significant mediastinal shift and volume loss on the right side, with prominent vascular markings only seen on the right side, (B) Chest CT scan showing right-sided volume loss with hypolucency, prominent right interstitial markings, subsegmental atelectasis, very small right pleural effusion and small right hilar and mediastinal adenopathy.
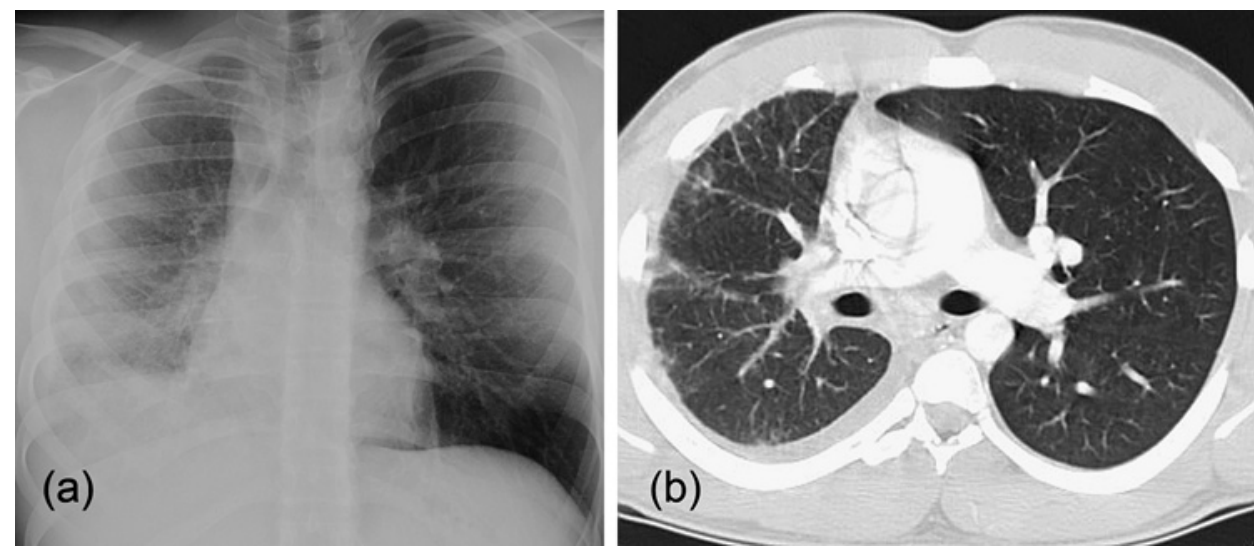